\title{
Mineral magnetite as precursor in the synthesis of multi-walled carbon nanotubes and their capabilities of hydrogen adsorption
}

\author{
Mauricio Morel ${ }^{a}$, Edgar Mosquera ${ }^{a, *}$, Donovan E. Diaz-Droguett ${ }^{b}$, \\ Nicolás Carvajal ${ }^{a}$, Martin Roble ${ }^{b}$, Vania Rojas ${ }^{a}$, \\ Rodrigo Espinoza-González ${ }^{c}$ \\ a Laboratorio de Materiales a Nanoescala, Departamento de Ciencia de los Materiales, FCFM, Universidad de Chile, \\ Av. Tupper, 2069, Santiago, Chile \\ ${ }^{\mathrm{b}}$ Instituto de Física, Facultad de Física, Pontificia Universidad Católica de Chile, Casilla 306, Santiago, Chile \\ ${ }^{c}$ Laboratorio de Materiales Avanzados Multifuncionales, Departamento de Ciencia de los Materiales, FCFM, \\ Universidad de Chile, Av. Tupper, 2069, Santiago, Chile
}

\section{A R T I C L E I N F O}

\section{Article history:}

Received 9 June 2015

Received in revised form

23 September 2015

Accepted 24 September 2015

Available online 17 October 2015

\section{Keywords:}

Green chemistry

Mineral magnetite

MWCNTs

$\mathrm{H}_{2}$ adsorption capabilities

\begin{abstract}
A B S T R A C T
Mineral magnetite was used as metallic oxide catalysts in the synthesis of Multi-Walled Carbon Nanotubes (MWCNTs) by Aerosol Assisted Chemical Vapor Deposition (AACVD). The structural and morphological information of MWCNTs was obtained by X-ray Diffraction (XRD), Raman Spectroscopy (RS), Scanning Electron Microscopy (SEM), and Transmission Electron Microscopy (TEM). The hydrogen storage capacity and the gas adsorption kinetics of the MWCNTs exposed to $\mathrm{H}_{2}$ at different pressures were determined using a quartz crystal microbalance (QCM). It was found that the hydrogen adsorption capacity was strongly dependent on the chemical, structural and morphological characteristics of the MWCNTs which, in turn, depend on the proportion of the starting materials (mineral magnetite and zeolite) used for the synthesis by AACVD. However, no a clear correlation was found between each one of these characteristics and the adsorption properties since the sample was affected by gas exposure during the $\mathrm{H}_{2}$ loading/unloading cycles. The maximum adsorption capacity was $1.76 \mathrm{wt} \%$ at $44 \mathrm{Torr}$ of $\mathrm{H}_{2}$ exposure pressure. The adsorption kinetics was determined by in situ monitoring the QCM resonance frequency. As expected, a faster $\mathrm{H}_{2}$ adsorption kinetics of the MWCNTs occurred when the sample was exposed to higher $\mathrm{H}_{2}$ pressures. In general, there are measurable $\mathrm{H}_{2}$ adsorption between $60 \mathrm{~s}$ and $100 \mathrm{~s}$ before reaching saturation.
\end{abstract}

Copyright $\odot$ 2015, Hydrogen Energy Publications, LLC. Published by Elsevier Ltd. All rights reserved.

\footnotetext{
* Corresponding author. Tel.: +56 2297 84795; fax: +56 26994119.

E-mail address: edemova@ing.uchile.cl (E. Mosquera). 


\section{Introduction}

During the last decade, there has been an increasing interest in the synthesis of carbon nanotubes (CNTs) mainly due to its versatility and functionality in a wide range of applications from electronics to medicine. CNTs are carbonaceous compounds with a unique tubular structure (single- or multiwalled), large specific surface area, and good chemical and thermal stability. These special characteristics of the CNTs provide a series of interesting properties and applications [1-3]. Recently, attention has been focused on the usage of CNTs as a safe hydrogen storage medium [3-8]. Nevertheless, studies on experimental quantification of hydrogen storage capacity of CNTs are still very few, and the hydrogen storage into CNTs and the factors affecting the adsorption remains still unclear $[5,8]$. Liu et al. pointed out that certain amount of hydrogen (less than 1.7 wt\% under a pressure of around $12 \mathrm{MPa}$ at room temperature) can be stored in CNTs [5], which indicate that CNTs cannot fulfill the benchmark of $6.5 \mathrm{wt} \%$ set by the U.S. Department of Energy (DoE) for hydrogen storage systems, established in 2010 [5-8]. The DoE targets set for the year 2020 [9] has been a hydrogen gravimetric capacity of $5.5 \mathrm{wt} \%$ with a volumetric capacity of $40 \mathrm{~g} / \mathrm{L}$, respectively. The storage by adsorption on carbon materials has definite advantages from the safety perspective such that some form of conversion is required to release the hydrogen for use. The research on hydrogen storage in carbon materials (graphene, graphene oxide (GO), and CNTs (single walled- and multi walled-CNTs)) was dominated by announcements of high storage capacities in carbon nanostructures. However, theoretical and experimental studies on hydrogen storage of CNTs and CNT-based hybrid structures are continually being studied [5,8,10-12]. The hydrogen storage capacity for carbon materials have been reported between 0.1 and $10 \mathrm{wt} \%$ [5]. However, the big challenge of finding a material capable of storing very high amounts of hydrogen, at ambient conditions as to make this fuel also economically viable has still to be overcome. For example, Aboutalebi et al. reported that two dimensional (2D) carbon materials such as graphene, graphene oxide (GO), and graphene oxide-multiwalled carbon nanotubes (GO-MWCNTs) composite can enhance the hydrogen storage [11]. They reported that the hydrogen storage capacity in GO-MWCNTs composites was improved up to $2.6 \mathrm{wt} \%$ at room temperature. The strong synergistic effect of the intercalation of MWCNTs as 1-D spacers within GO frameworks resulted in a high hydrogen storage capacity. However, Jiang et al. point out that certain metal organic frameworks-multiwalled carbon nanotube (MOF-MWCNTs) hybrid composites could enhance hydrogen storage capacity [12]. Hybrid composites can store $2.02 \mathrm{w} \%$ at $77 \mathrm{~K}$ under 1 bar. On the other hand, it is believed that modification of CNTs by adding metals (such as $\mathrm{Ni}, \mathrm{Fe}, \mathrm{Co}, \mathrm{Cd}, \mathrm{Cu}, \mathrm{Au}, \mathrm{Ag}$, and Pt) $[13,14]$ and/or metal oxides (such as $\mathrm{Fe}_{2} \mathrm{O}_{3}, \mathrm{Fe}_{3} \mathrm{O}_{4}, \mathrm{ZnO}$, and $\mathrm{TiO}_{2}$ ) $[15,16]$ to the carbon structure provides the most suitable methods for enhancing the hydrogen storage capacity and facilitating the practical use of CNTs in vehicles [3]. Metals have been intensively studied as catalyst for the growth of CNTs which can be expensive or not friendly to the environment. In the case of metal oxides such as iron oxide, which present lower cost and toxicity, are widely used to incorporate magnetic properties in CNTs [17-23]. A number of new compounds are continuously being introduced as hydrogen storage materials, and the hydrogen adsorption mechanism and hydrogen adsorption sites are being studied $[3,4]$.

In this research work, Multi-Walled Carbon Nanotubes (MWCNTs) were synthesized by an Aerosol Assisted Chemical Vapor Deposition (AACVD) process using low cost raw material (Chilean mineral magnetite), with and without zeolite as support, and camphor as the carbon source. The MWCNTs obtained were characterized by X-ray diffraction, Raman spectroscopy, and electron microscopy (SEM and TEM) techniques and the hydrogen storage capacity were studied. The hydrogen adsorption capacity of the as-prepared MWCNTs at room temperature was determined by means of a quartz crystal microbalance using different pressures of hydrogen exposure. The maximum adsorption capacity was $1.76 \mathrm{wt} \%$ at 44 Torr of hydrogen exposure pressure at room temperature, which indicate that the MWCNTs cannot fulfill the benchmark set by the US Department of Energy (DoE) for 2020 [9].

\section{Experimental details}

\section{Synthesis of MWCNTs}

MWCNTs were grown using an AACVD method. The reaction was carried out in a home-made ultrasonic spray pyrolysis system. The mineral magnetite catalyst ( $0.5 \mathrm{~g}$ of total mass) was located in the center of a quartz tube of $25.4 \mathrm{~mm}$ diameter size and $510 \mathrm{~mm}$ long. The catalyst with or without zeolite (support) was placed inside a furnace with $15 \mathrm{~cm}$ of heat zone. A solution of camphor in ethanol $(10 \mathrm{ml}-2 \% \mathrm{w} / \mathrm{w})$ as carbonaceous source was placed in the ultrasonic nebulizer. The proportion of catalyst/support used in the synthesis is shown on Table 1 . The furnace was heated to $800{ }^{\circ} \mathrm{C}$ and the nebulization was maintained for $30 \mathrm{~min}$. Afterwards, the system was cooled down to room temperature (RT) using the own thermal inertia of the equipment. When the system was cooled to RT, a blackened powder was obtained in the middle of quartz tube, which was collected for characterization without purification process, see Fig. 1.

\section{Sample characterization}

The crystalline structure of the powders was determined using a Bruker D8 X-ray diffractometer (XRD) with $\mathrm{CuK} \alpha_{1,2}$ radiation operated at $40 \mathrm{kV}$ and $30 \mathrm{~mA}$. Raman spectra of the samples were obtained at RT on a LabRam 010 from ISA to identify the structure and degree of crystallinity of the CNTs.

Table 1 - Description of the samples regarding to the content of mineral magnetite and zeolite and yields obtained in the synthesis by AACVD.

Sample Magnetite (\%) Zeolite (\%) Others (\%) $\quad$ Yield (\%)

\begin{tabular}{rrrrr}
\hline M1 & 98 & - & 2 & 39.1 \\
M2 & 80 & - & 20 & 34.4 \\
M3 & 78 & 20 & 2 & 27.4 \\
\hline
\end{tabular}




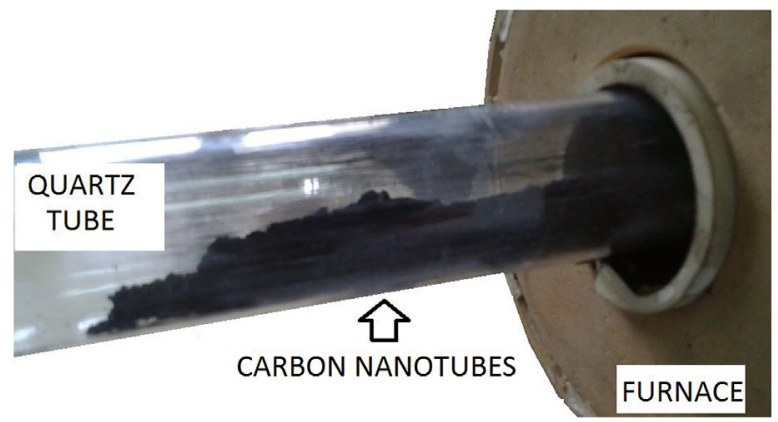

Fig. 1 - Image of MWCNTs powder grown by AACVD inside the quartz tube.

A He-Ne laser with a wavelength of $632.8 \mathrm{~nm}$ at $5.5 \mathrm{~mW}$ was used as the Raman excitation source. A scanning electron microscope (SEM, FEI Quanta 250) was used to characterize the morphology of the synthesized MWCNTs. Structural information was acquired by high-resolution transmission electron microscopy (HR-TEM) images using a Tecnai F20 FEG-S/ TEM, operated at $200 \mathrm{kV}$. TEM samples were prepared by sonication of the powder in isopropyl alcohol and few drops of the resultant suspension were dropped on an ultrathin holey carbon-coated $\mathrm{Cu}$ grid.

For the $\mathrm{H}_{2}$ adsorption studies the MWCNTs powders were deposited at RT on the top-face of a microbalance quartz crystal (QC) used as supporting substrate. The powder was dispersed in isopropyl alcohol by sonication using an ultrasonic bath for $7 \mathrm{~min}$. The suspension was deposited onto the QC and then dried at RT. Then, the QC was located in the head of a quartz crystal microbalance system (from MDC model SQM-310) placed inside a vacuum chamber. The chamber was pumped down to $7 \times 10^{-6}$ Torr using turbo and rotatory pumps operating in series. A gate valve placed between the chamber and the turbo pump to isolate the chamber from the vacuum, allowed pressurizing with $\mathrm{H}_{2}$ (Indura, 99.995\%, $\mathrm{O}_{2}<5$ ppm, $\mathrm{H}_{2} \mathrm{O}<8 \mathrm{ppm}, \mathrm{CO}_{2}+\mathrm{CO}<4 \mathrm{ppm}, \mathrm{N}_{2}<20$ ppm and THC $<5$ ppm) injecting it through a needle valve. The mass change upon hydrogen adsorption were determined monitoring in-situ the changes in the resonance frequency of the QC as function of time while the sample was exposed to hydrogen for $8 \mathrm{~min}$. After $\mathrm{H}_{2}$ exposure, the chamber was again pumped down to $7 \times 10^{-6}$ Torr, and the process was repeated injecting hydrogen until reaching a higher pressure. The pressures between 3 and 55 Torr were monitored with a capacitive gauge (Baratron from MKS instruments) in the different hydrogenation cycles.

The relationship between the mass added to the QC, $\Delta m$, due to the $\mathrm{H}_{2}$ adsorption on the MWCNTs and the shift in its resonance frequency, $\Delta f$, is represented by the Sauerbrey's equation [24-26]:

$\Delta=-\frac{2 f^{2}}{\mathrm{~A} \sqrt{\rho \times \mu}} \Delta m$

where $f$ is the QC resonant frequency, $\rho$ is the density, $\mu$ is the bulk modulus of the QC and A is the area covered by the mass. This equation indicates that a negative variation of the resonance frequency is due to a mass gain by the sample. Details about the use of this equation and method for the determination of mass gained by a QC using a quartz crystal microbalance system can be found in Ref. [27]. Another study carried out by this group where a quartz crystal microbalance was used for gas adsorption studies can be found in Ref. [8].

\section{Results and discussion}

It was found that for the synthesis of MWCNT using a mixture of camphor/alcohol, the performance was dependent on the catalyst material and support used $[8,28]$. However, from the viewpoint of the present research, the results obtained using camphor/alcohol as precursor material, are comparable with other works in the production of CNTs on a large scale. Kumar et al. [28] reported mass production of MWCNTs using a zeolite supported metal catalyst. Based on that work, initially we used a metal loading for nickel catalyzed reactions [8], but the yield was poor compared to using magnetite like catalyst. The weight yield of the synthesis was the proportion between organic mass with respect to total powder mass (Table 1). However, when we used $98 \%$ mineral magnetite (sample M1) and $80 \%$ (sample M2) without zeolite as support, we found that the yield of MWCNTs was higher (see Table 1). All powders were analyzed by X-ray diffraction (Fig. 2), which showed a change in the structure of the magnetite attributed to the reduction of iron present in the magnetite $\left(\mathrm{Fe}_{3} \mathrm{O}_{4}\right)$ to iron carbide $\left(\mathrm{Fe}_{3} \mathrm{C}\right)$ phase, and only a little portion corresponding to ferrous oxide $(\mathrm{FeO})$. This is possible because of the proximity of the particles with carbonaceous material.

In all samples (M1, M2, and M3), the diffraction peak assigned to graphitic structure was observed at $26.34^{\circ}$, which is related to the graphitic plane $\left(\begin{array}{lll}0 & 0\end{array}\right)$ or to the wall-to-wall distance in MWCNTs [29]. Theoretical calculations made by Liu et al. [30] showed that the shift from $26.27^{\circ}$ to $26.55^{\circ}$ of the Bragg angle $(2 \theta)$ is related to the curvature of the crystallites due to increased graphene layers. In addition, the experimentally observed X-ray reflection for graphite (totally flat) is

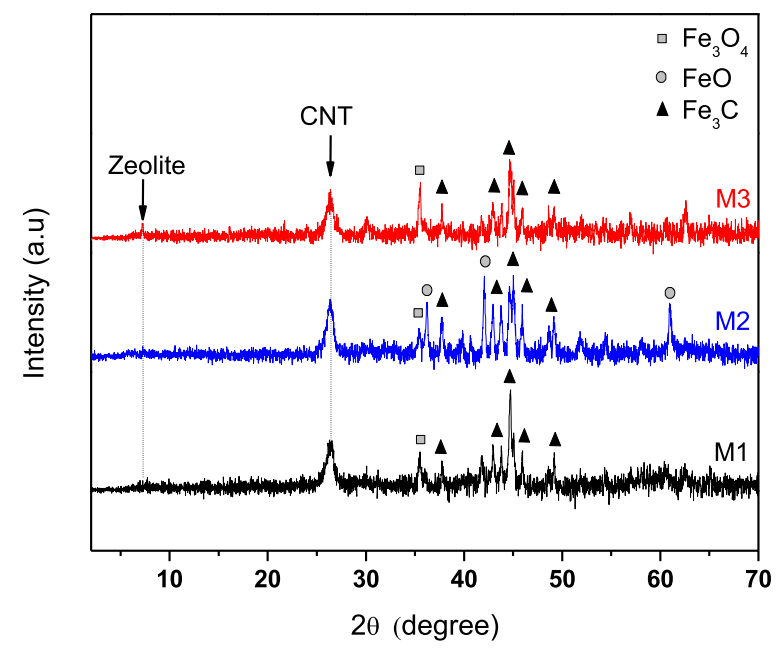

Fig. 2 - X-ray diffraction patterns of the samples (M1, M2, and M3) without purification. 
$26.5^{\circ}$, whereas for single-walled CNTs (SWCNTs, totally curve) the Bragg angle $(2 \theta)$ is less than $26^{\circ}$. A closer look at $(002)$ peak shows an asymmetry in line shape. Therefore, the $\left(\begin{array}{ll}0 & 0\end{array}\right)$ peak has been fitted with two Gaussian, as shown in Fig. 3 and Table 2. The asymmetry can be assigned to the presence of different crystalline species and may arise from the different relative orientations of successive layer of MWCNTs forming walls of different chiralities [31]. However, all patterns exhibited two peaks with a larger percent near to $26.34^{\circ}$, independent of the sample. Our results from XRD analysis are consistent with theoretical calculations previously reported [30].

Raman spectroscopy was performed to confirm the degree of crystallinity of the MWCNTs. Fig. 4 shows that M1 sample presents a mild shift of the D-band and G-band frequency to higher wavenumber $\left(1331 \mathrm{~cm}^{-1}\right.$ and $\left.1587 \mathrm{~cm}^{-1}\right)$ with respect to M2 (1317 $\mathrm{cm}^{-1}$ and $\left.1569 \mathrm{~cm}^{-1}\right)$ and M3 (1326 $\mathrm{cm}^{-1}$ and $1570 \mathrm{~cm}^{-1}$ ) samples, respectively. Thus, this shift in M1 sample is attributed to a lower inter-tube van der Waals interaction. To explain the mild shift of D-band and G-band frequency with diameter of MWCNTs, it is clear that when the number of walls increases the inter-tube spacing decreases. Therefore, we can see that the D-band is distinct in all samples, showing a dependence on the diameter. In addition, the samples present a lower intensity of G-band that is comparable to the intensity of the D-band, which is typical in MWCNT samples. With respect to the D-band, this vibrational
Table 2 - Fitting results of the XRD peak around $26^{\circ}$ and Raman intensity ratio obtained from the samples.

\begin{tabular}{|c|c|c|c|c|c|}
\hline \multirow[t]{2}{*}{ Sample } & & \multicolumn{3}{|c|}{$\begin{array}{l}\text { XRD analysis of the } \\
\text { diffraction peak } \\
\left(\sim 26.34^{\circ}\right)\end{array}$} & \multirow{2}{*}{$\begin{array}{c}\begin{array}{c}\text { Raman intensity } \\
\text { ratio }\end{array} \\
\left(\mathrm{I}_{\mathrm{D}} / \mathrm{I}_{\mathrm{G}}\right)\end{array}$} \\
\hline & & Peak & $2 \theta$ & Area (\%) & \\
\hline \multirow[t]{2}{*}{ CNT\#16 } & M1 & 1 & $26.32^{\circ}$ & 93.44 & 1.43 \\
\hline & & 2 & $26.58^{\circ}$ & 6.56 & \\
\hline \multirow[t]{2}{*}{ CNT\#14 } & M2 & 1 & $26.18^{\circ}$ & 50.32 & 0.93 \\
\hline & & 2 & $26.40^{\circ}$ & 49.68 & \\
\hline \multirow[t]{2}{*}{ CNT\#17 } & M3 & 1 & $26.32^{\circ}$ & 65.49 & 0.96 \\
\hline & & 2 & $26.36^{\circ}$ & 34.51 & \\
\hline
\end{tabular}

mode is forbidden in a perfect graphitic material and only becomes active in presence of disorder [32]. The full width at half maximum (FWHM) of the D-band gradually decreases as the tube diameter increases [31]. The FWHM of the D-band of M1 sample is relatively large $\left(\sim 90 \mathrm{~cm}^{-1}\right)$ in comparison with M2 $\left(\sim 50 \mathrm{~cm}^{-1}\right)$ and M3 $\left(\sim 62 \mathrm{~cm}^{-1}\right)$ samples, respectively. However, recent reports indicate that various forms of carbon can be distinguished by the position and the FWHM of the Dband [31]. For example, the FWHM of Amorphous carbon has been reported to be greater than $100 \mathrm{~cm}^{-1}$, while for SWCNTs, the FWHM is about $10-30 \mathrm{~cm}^{-1}$ (D-band position at 1285-1300 $\left.\mathrm{cm}^{-1}\right)$. Previously it has been reported that MWCNTs behave similar to the crystalline graphite-like
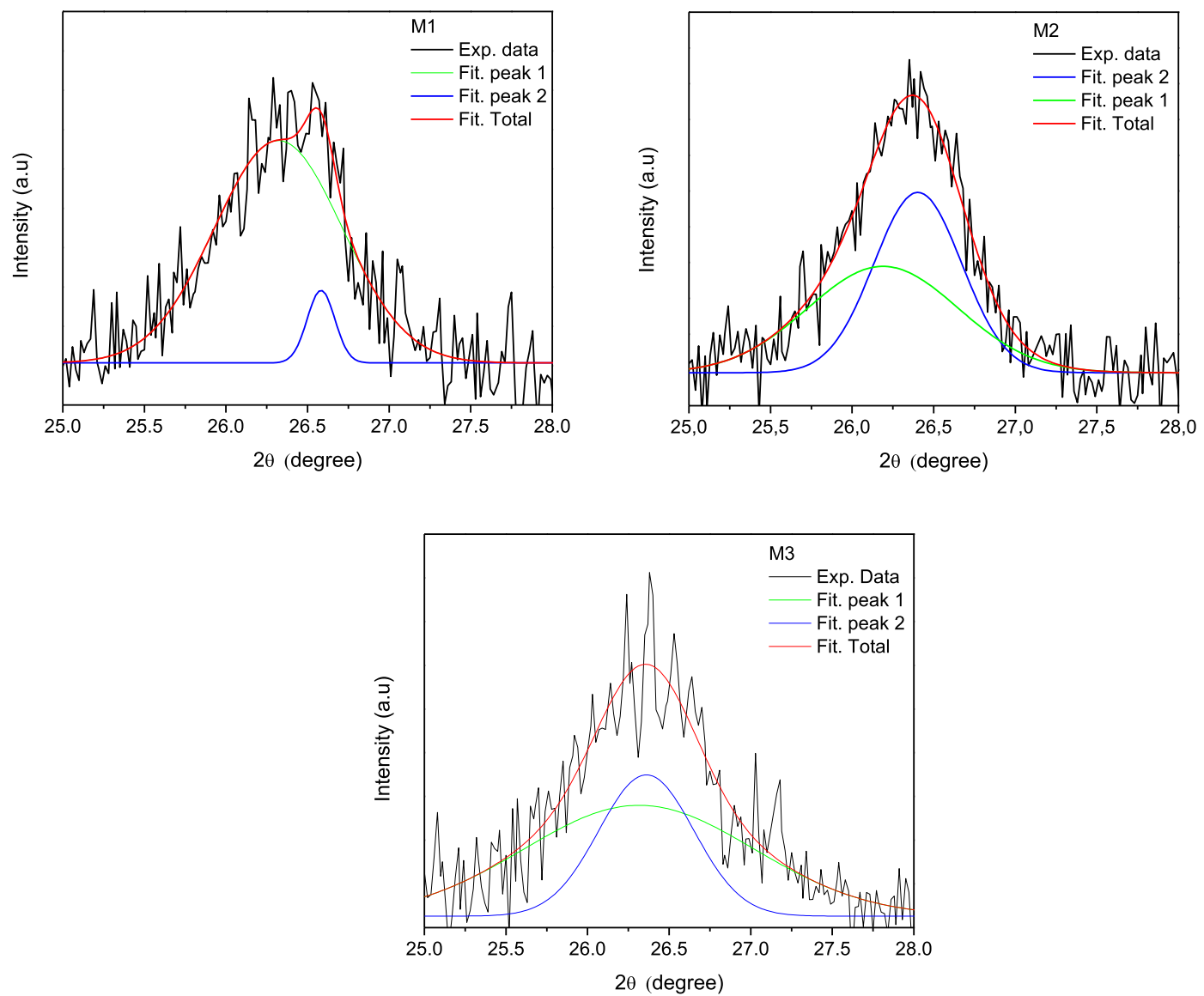

Fig. 3 - Fitting of the XRD (002) peak obtained from the samples (M1, M2, and M3). 


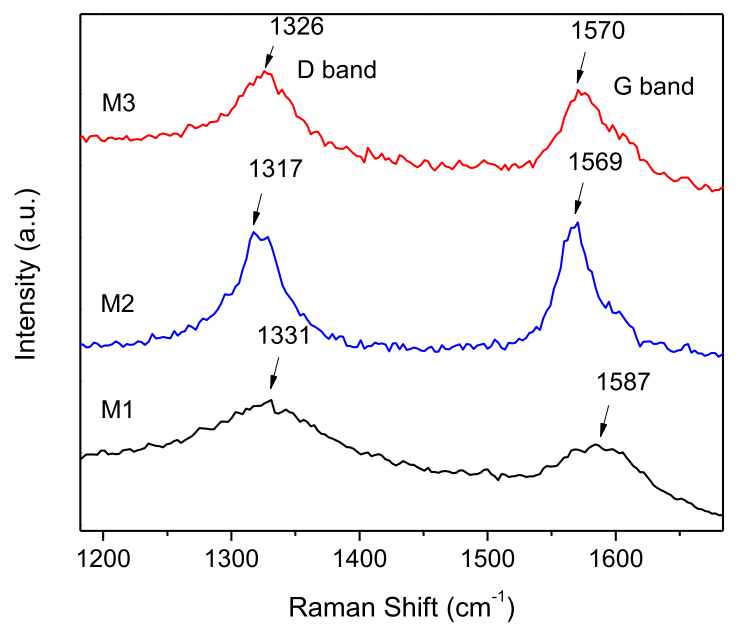

Fig. 4 - Raman spectra of MWCNTs (M1, M2, and M3) grown by AACVD.

forms, which have a FWHM of about $30-60 \mathrm{~cm}^{-1}$ and a typical position of $1305-1330 \mathrm{~cm}^{-1}[33,34]$. In our samples, the Raman results showed a FWHM intermediate between amorphous carbon and crystalline graphitic-like forms of the order of $\sim 60-90 \mathrm{~cm}^{-1}$ for M1 and M3, respectively. Whereas M2, presented a FWHM of D-band close to the crystalline graphiticlike form with less amorphous carbon in comparison with M1 and M2 samples.

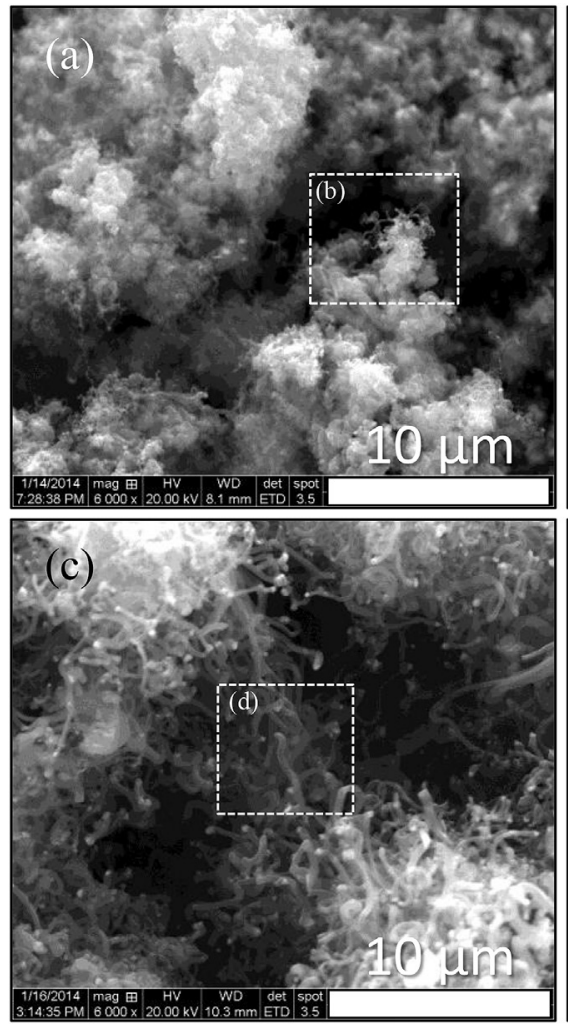

On the other hand, the intensity ratio $\left(\mathrm{I}_{\mathrm{D}} / \mathrm{I}_{\mathrm{G}}\right)$ is commonly used as indicative of the degree of crystallinity in CNTs; values closer to one, indicate that there are more defects contained in graphene wall and a lower the degree of crystallinity of the carbonaceous material [8]. In Table 2, we display the intensity ratio $\left(\mathrm{I}_{\mathrm{D}} / \mathrm{I}_{\mathrm{G}}\right)$ of samples: $\mathrm{M} 1, \mathrm{M} 2$, and $\mathrm{M} 3$, respectively. According to the $I_{D} / I_{G}$ ratio all samples present a high degree of defects, but the sample with higher yield (M1) presents a value higher than 1. Cho et al. [35] showed that high values of the ratio $I_{D} / I_{G}$ indicate that the nanotubes present more disorder, defects, and amorphous carbon, which is in agreement with our results.

SEM images of the as-prepared MWCNTs (M1 and M3) are shown in Fig. 5(a)-(d)). The catalytic particles are not revealed by this technique. The MWCNTs agglomerates look similar to small balls of wool with some hairs out. The Fig. 5(b) and (d)), correspond to a higher magnification of the images $5 a$ ) and $5 c$ ), respectively.

Fig. 6 shows TEM and HRTEM images of MWCNTs. Fig. 6(a)-(c) show images of the M3 sample. It can be seen from images 6 (a) and (b) that numerous nanoparticles with size smaller than $50 \mathrm{~nm}$ are adhered to the outer wall of the MWCNTs. The X-ray analysis indicates that these particles are generated by a reduction of iron in the mineral magnetite $\left(\mathrm{Fe}_{3} \mathrm{O}_{4}\right)$ to iron carbide $(\mathrm{FeC})$ or ferrous oxide $(\mathrm{FeO})$, respectively. Fig. 6 (c) clearly shows a MWCNT with $\sim 9 \mathrm{~nm}$ of multiwall corresponding to $\sim 27$ concentric nanotubes. Fig. 6(d)-(f), the MWCNTs displayed corresponds to nanotubes with $\sim 4.3 \mathrm{~nm}$ of multi-wall corresponding to $\sim 13$ concentric
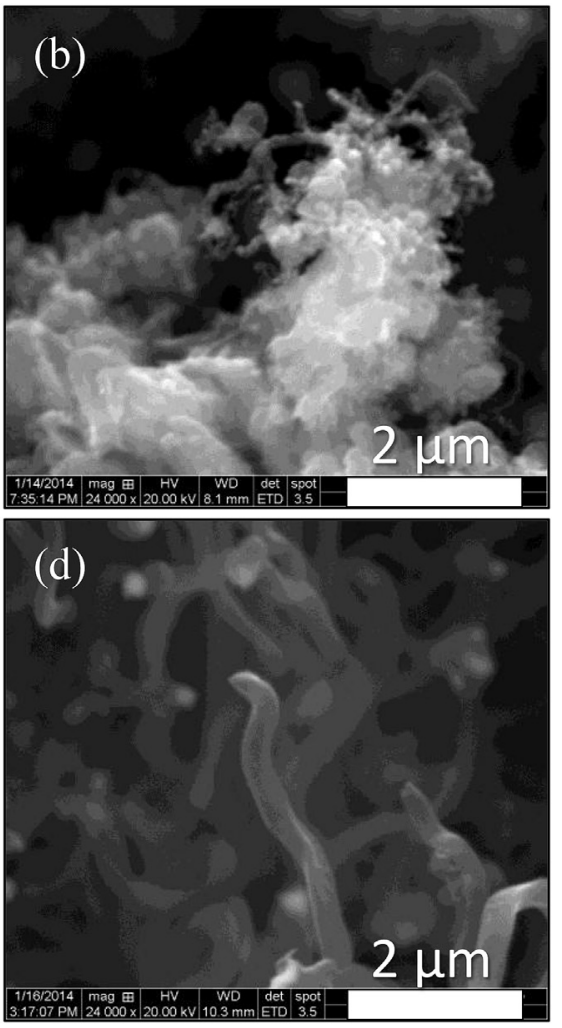

Fig. 5 - SEM images of MWCNTs produced by AACVD using a mixture camphor/alcohol. (a,c) Low magnification SEM images of the samples M1 and M3. (b, d) The dotted frame in a) and c) is shown magnified to display the morphology of the MWCNTs. 


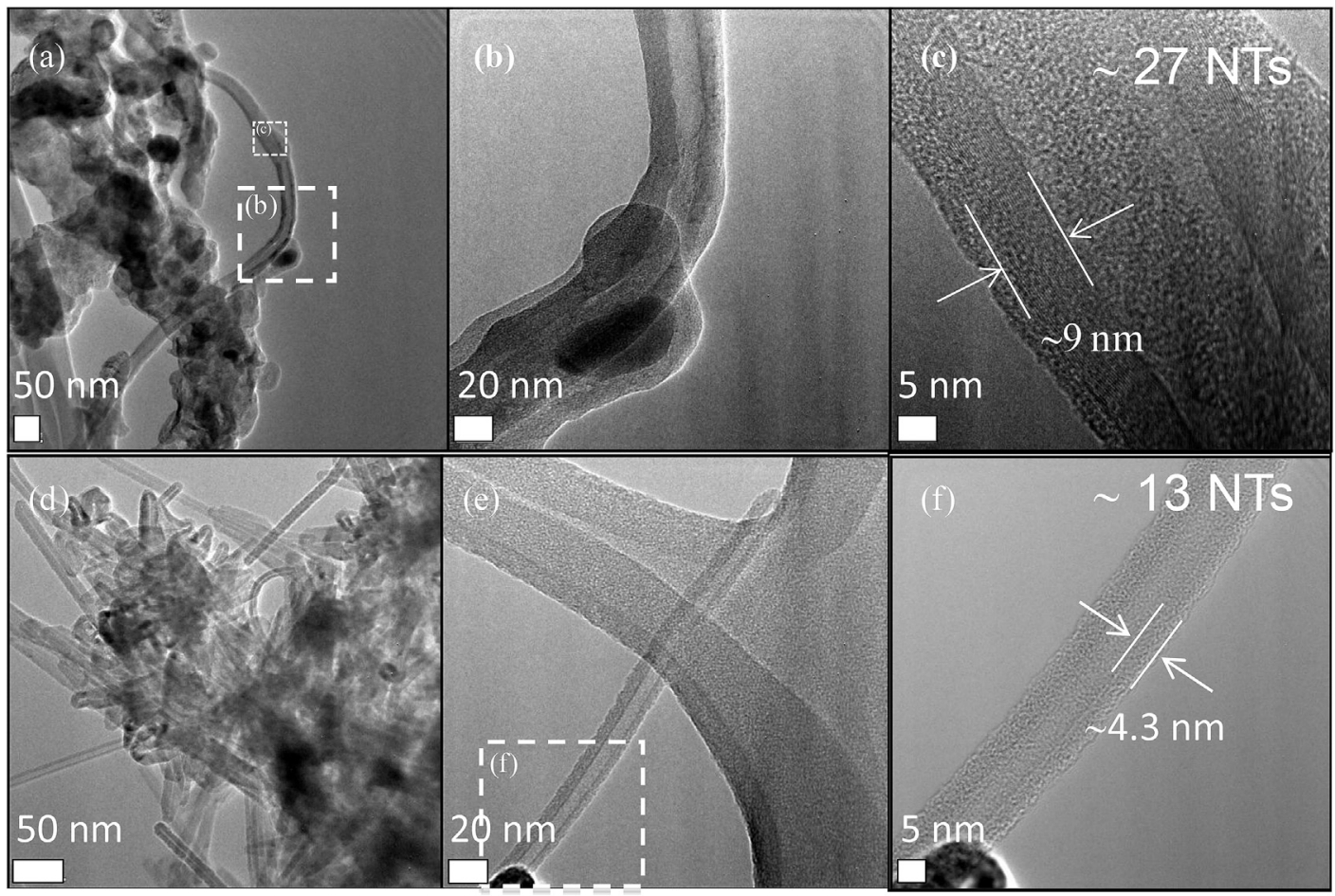

Fig. 6 - (a, d) TEM images of the samples M3 and M2. (b, c) The dotted frames in (a) are magnified at (b) and (c). (e) Shows the straight carbon nanotube, and (f) is a higher resolution image (zoom) from the dotted frame in (e).

nanotubes; in this case, the samples were synthesized with mineral magnetite (M2 sample) without zeolite. The average diameter of M2 and M3 samples is $20 \mathrm{~nm}$ and $40 \mathrm{~nm}$, respectively. HRTEM images shown in Fig. 6 show that the interplanar spacing varies as well with the diameter of MWCNTs.

The hydrogen storage capability of the MWCNTs grown by this AACVD technique was also studied. No pretreatments were carried on the samples for evaluating their performance regarding $\mathrm{H}_{2}$ adsorption. There are works where the $\mathrm{H}_{2}$ adsorption properties of preformed carbon nanotubes are evaluated in very particular condition of the sample, where before the measurements of $\mathrm{H}_{2}$ adsorption, the samples underwent previously a purification processes to remove the metal particles used as catalyst [36], or were subjected to annealing at high temperature and ions doping to increase the $\mathrm{H}_{2}$ adsorption capacity [37], or were subjected to ultrasonic treatments [38] to cut the carbon nanotubes, specially, their close ends, so enhancing the hydrogenation of the whole carbon nanotube.

Fig. 7 shows a representative behavior of the quartz crystal (QC) resonance frequency as function of time recorded at 3, 23 and 43 Torr for the M3 sample. However, the $\mathrm{H}_{2}$ adsorption studies on all samples were carried out using increasing exposure pressures from 3 torr up to 55 Torr with pressure increases of around 5 Torr after each cycle of $\mathrm{H}_{2}$ loading/ unloading. The three curves of Fig. 7 have a similar behavior. Before injecting hydrogen to the chamber, the QC resonance frequency started to be recorded under vacuum conditions $\left(7 \times 10^{-6}\right.$ Torr $)$. Under this condition, the QC resonance frequency remains constant as shown in Fig. 7. After $60 \mathrm{~s}$ the chamber was rapidly filled with $\mathrm{H}_{2}$ until reaching a working pressure. In Fig. 7 is possible to see that as soon as hydrogen is injected to the chamber, the QC resonance frequency rapidly drops until reaching a constant value (saturation condition). In general, the $\mathrm{H}_{2}$ adsorption kinetics on the MWCNTs occurred in less than 100s, a value that decreases as the exposure pressure increases, as indicated in Fig. 7. The frequency shift, $\Delta f$, obtained from the values of the QC resonance frequency under vacuum condition and saturation condition, is used in the Saurbrey's equation to calculate the $\mathrm{H}_{2}$ mass adsorbed by the MWCNTs under a certain $\mathrm{H}_{2}$ exposure pressure.

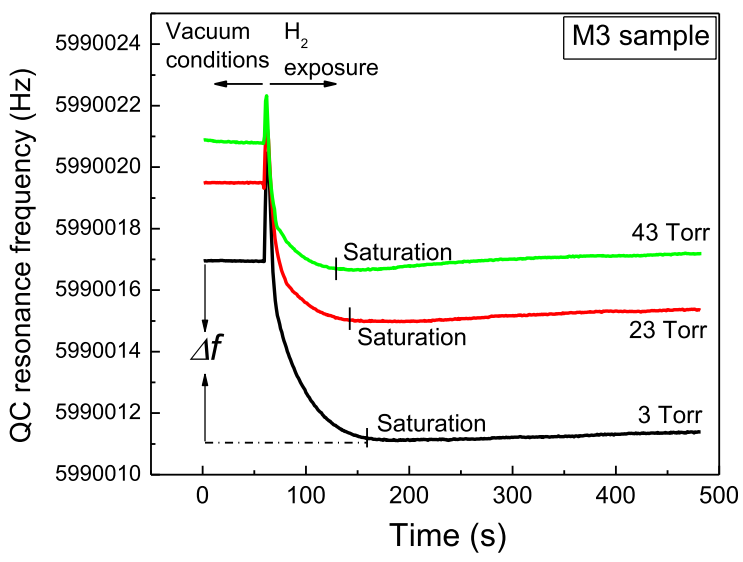

Fig. 7 - Representative curves of the changes of the QC resonance frequency measured at different $\mathrm{H}_{2}$ exposure pressures for sample M3. 
A very important aspect to be considered in our computations is that the simple hydrogen injection process into the vacuum chamber induces a shift of the QC resonance frequency not associated to mass gain by hydrogen adsorption on the samples, which can be observed employing a bare quartz crystal. To rule out this effect and a possible error in the determination of the amount of hydrogen adsorbed by the MWCNTs a bare microbalance quartz crystal was exposed to the same cycles of $\mathrm{H}_{2}$ loading/unloading performed on the MWCNTs samples. Through this study we found that the QC resonance frequency was shifted about $3.3 \mathrm{~Hz}$ when the chamber was filled with hydrogen. Therefore, this frequency shift was subtracted from the $\Delta f$ values determined recoded on the MWCNT samples.

As revealed in Fig. 7, the QC resonance frequency measured under vacuum conditions slightly increased after each cycle of $\mathrm{H}_{2}$ loading/unloading. In general, all samples exhibited this behavior. This increase of the QC resonance frequency is related to mass losses from the sample after each cycle. Probably the $\mathrm{H}_{2}$ adsorption and then desorption produced by the $\mathrm{H}_{2}$ unloading from the chamber drags some volatile compounds occluded in the graphitic walls of the MWCNTs. In this sense, the M1 sample exhibited the highest variation of its QC resonance frequency measured under vacuum condition after the cycles of $\mathrm{H}_{2}$ loading/unloading, about $34 \mathrm{~Hz}$. The M2 sample had a variation of only $\sim 2 \mathrm{~Hz}$ and the M3 sample of $\sim 4.5 \mathrm{~Hz}$.

A summary of the $\mathrm{H}_{2}$ adsorption capacity of all the samples as a function of increasing pressure ranging between 3 and 55 Torr is shown in Fig. 8. Fig. 8 shows as well the weight percentage (wt\%) of hydrogen adsorbed at room temperature by the MWCNTs when exposed to successive cycles of $\mathrm{H}_{2}$ loading/unloading.

Fig. 8 shows that the three samples of MWCNTs exhibit different $\mathrm{H}_{2}$ adsorption behaviors. The sample M1 reached $0.41 \mathrm{wt} \%$ during the first exposure using just 5.7 Torr of $\mathrm{H}_{2}$, value that did not vary significantly up to 28 Torr. After this pressure the $\mathrm{H}_{2}$ storage capacity slightly drops down $0.04 \mathrm{wt} \%$ at 43 Torr. On the contrary, the sample M2 showed a notable

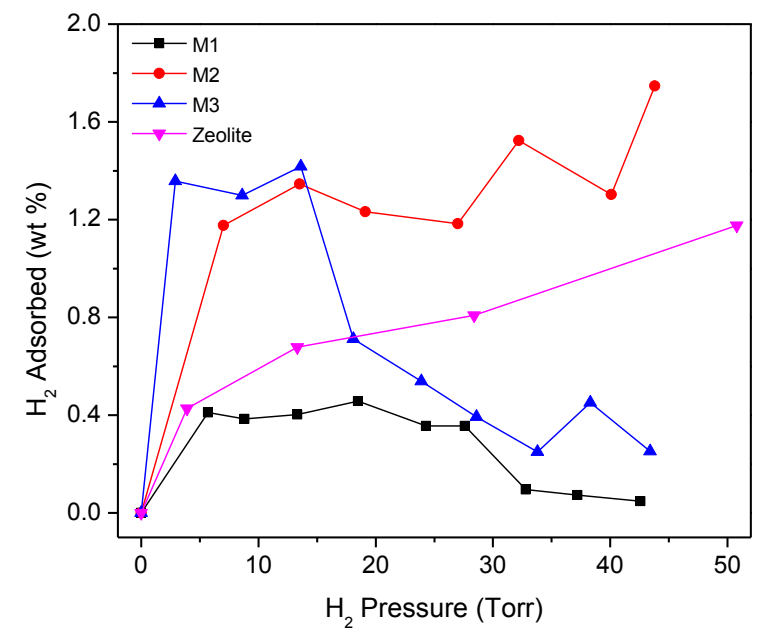

Fig. 8 - Hydrogen storage capacity at RT from the MWCNTs exposed to various $\mathrm{H}_{2}$ pressures. A sample composed only of zeolite was used for comparison. dependence on the $\mathrm{H}_{2}$ exposure pressure. This sample showed a gradual increase of the $\mathrm{H}_{2}$ amount adsorbed as pressure increased reaching a maximum value of about 1.76 at the highest exposure pressure of 44 Torr. This weight percentage is comparable or higher than other values of $\mathrm{H}_{2}$ storage capacities at RT reported by non-pretreated/doped carbon nanotubes [5-8,36,39-41]. In the case of M3 sample, the weight percentage values of $\mathrm{H}_{2}$ adsorbed increased significantly between 3 and 14 Torr reaching a maximum value of 1.42 at 14 Torr, as depicted in Fig. 8. At higher exposure pressure, the amount of adsorbed $\mathrm{H}_{2}$ dropped $0.25 \mathrm{wt} \%$ at 43.4 Torr. The high values between 3 and 14 Torr could be attributed to a sudden gas filling of the MWCNTs and voids generated among the agglomerated CNTs as well as to a stress effect of the first monolayer of adsorbed $\mathrm{H}_{2}$ leading to a higher value of the QC resonance frequency and, therefore, appearing as mass gained by the sample $[8,42]$. Finally, a sample of pure zeolite was used to study its effect on the $\mathrm{H}_{2}$ adsorption. Its curve indicates that the microporous aluminosilicate particles indeed adsorb hydrogen, and the amount of $\mathrm{H}_{2}$ adsorbed increases with increasing pressures. The porous structure of the zeolite, with pore diameter as small as $2 \mathrm{~nm}$, yields a high specific surface area where the pore-channels formed help to provide more adsorption sites for the $\mathrm{H}_{2}$ molecule. However, this fact does not help to understanding the $\mathrm{H}_{2}$ adsorption behaviors, for example, of the samples M2 and M3, where the first one was grown without zeolite whereas the second one used zeolite as support. However, as mentioned above, we found a different behavior among the samples after the cycles of $\mathrm{H}_{2}$ loading/unloading that could provide some explanation about the difference existing on the curves of $\mathrm{H}_{2}$ adsorption shown in Fig. 8. The variation of $\sim 34 \mathrm{~Hz}$ found in the M1 sample measured in vacuum condition after the $\mathrm{H}_{2}$ loading/ unloading cycles at different pressures, revealed that this sample was the most affected by $\mathrm{H}_{2}$ losing part of its initial mass. This fact could explain the poor performance regarding the $\mathrm{H}_{2}$ adsorption capacity, specially, during the last exposure pressures (28-43 Torr). The M3 sample exhibited a variation of $\sim 4.5 \mathrm{~Hz}$ indicating, a moderate effect of the gas on the sample mass but probably responsible of its early drop of the $\mathrm{H}_{2}$ adsorption capacity after exposure to 20 Torr. On the other hand, the M2 sample exhibited the lowest variation of $\sim 2 \mathrm{~Hz}$, revealing a poor effect of $\mathrm{H}_{2}$ successive exposure on the initial characteristics of the sample. Probably, this fact leads to a $\mathrm{H}_{2}$ adsorption behavior for the M2 sample as shown in Fig. 8, where the $\mathrm{H}_{2}$ adsorption capacity, increases with the increasing exposure pressure, as expected. In summary, the different $\mathrm{H}_{2}$ adsorption behaviors could be explained due to the gas effect on the initial sample mass after the successive cycles of $\mathrm{H}_{2}$ exposure. However, the reason of the mass changes of the sample and probable modifications of their initial chemical characteristics and adsorption sites due to $\mathrm{H}_{2}$ successive exposure, requires further investigation. For this reason, our group evaluated first the $\mathrm{H}_{2}$ adsorption properties of MWCNTs grown by aerosol-assisted CVD method since for a forthcoming work these adsorption properties will be measured on purified MWCNTs grown by the same synthesis method. Other researchers have reported already the purification effect on the $\mathrm{H}_{2}$ adsorption properties on carbon nanotubes [43], where the functional groups attached to the 
surface of the nanotubes can retard the process of $\mathrm{H}_{2}$ adsorption by reducing the available surface area. However, the kinetics of the adsorption process between purified and non-purified carbon nanotubes, the role of the functional groups attached on the nanotubes, and the effect of the $\mathrm{H}_{2}$ exposure cycles required further study.

On the other hand, the reason for carrying out the gas adsorption measurements at low pressures between 3 and 55 Torr is twofold. First, the QC resonance frequency is very sensitive to temperature and the use of high pressures, for example, near the atmospheric pressure would induce, at least in the transient, a temperature variation of the $\mathrm{QC}$ which it is kept, in our case, at $18^{\circ} \mathrm{C}$ by a cooling system. This temperature change would lead to a variation of its resonance frequency. Therefore, the only gas adsorption effect would be hard to identify during the first seconds of the gas injection process. For this reason, the maximum resonance frequency shift of the QC $(\sim 3.3 \mathrm{~Hz})$ due only to the $\mathrm{H}_{2}$ injection was determined for our working pressure range, as previously mentioned. The second reason of measuring within the range of 3 up to 55 Torr is that it allows us comparing the $\mathrm{H}_{2}$ adsorption capacity with other carbon samples that were measured near the same pressure range using the QC microbalance technique. In a previous work, our group reported a $\mathrm{H}_{2}$ adsorption maximum value of $2.1 \mathrm{wt} \%$ achieved at 43 Torr of exposure pressure on MWCNTs grown by aerosol-assisted CVD method using $\mathrm{Ni}$ as a catalyst [8]. On the other hand, N. Aomoa et al. reported a $\mathrm{H}_{2}$ adsorption maximum value of about 0.8 wt\% at 25 Torr on carbon nanoparticles grown by plasma-assisted single-step process [44].

\section{Conclusions}

MWCNTs have been successfully grown by AACVD using a camphor/ethanol mixture and mineral magnetite as catalyst with or without zeolite as precursors. Using a low cost, friendly environment and easy to purify iron-based catalyst instead of a nickel system, large and straight MWCNTs with $20 \mathrm{~nm}$ in diameter have been produced. Some defects and low degree crystallinity are observed on the graphitic layers. The hydrogen adsorption capacity was strongly dependent on the chemical, structural and morphological characteristics of the MWCNTs which in turn depended on the ratio of the mineral magnetite and zeolite. However, no clear correlation was found between each one of these characteristics and the adsorption properties since the sample was affected by gas exposure during the $\mathrm{H}_{2}$ loading/unloading cycles and, therefore, we found a maximum value of adsorption capacity of $1.76 \mathrm{wt} \%$ at 44 Torr of $\mathrm{H}_{2}$. As expected, higher $\mathrm{H}_{2}$ exposure pressures leads to a faster $\mathrm{H}_{2}$ adsorption kinetics of the MWCNTs. We found that the $\mathrm{H}_{2}$ adsorption process occurred between $60 \mathrm{~s}$ and $100 \mathrm{~s}$ up to reaching the saturation condition of the sample.

\section{Acknowledgments}

The financial support of the Government Research Agencies (FONDECYT Grant N ${ }^{\circ} 1150475$ and $N^{\circ} 11130555$, and CONICYT
Grant $N^{\circ}$ ACT1117 and ID14I10124) of Chile, are gratefully acknowledged. We thank Prof. A. Cabrera from Physics Institute of the Pontificia Universidad Católica de Chile for using the equipments from his laboratory for this research. The author (EM) is grateful to Dr. F. Gracia and Dr. R. Muñoz from FCFM-Universidad de Chile, for comments on the manuscript.

\section{Appendix A. Supplementary data}

Supplementary data related to this article can be found at http://dx.doi.org/10.1016/j.ijhydene.2015.09.112.

\section{R E F E R E N C E S}

[1] Franklin AD. The road to carbon nanotube transistors. Nature 2013;498:443-4.

[2] Wang JT-W, Cabana L, Bourgognon M, Kafa H, Protti A, Venner K, et al. Magnetically decorated multiwalled carbon nanotubes as dual MRI and SPECT contrast agents. Adv Funct Mater 2014;24:1880-94.

[3] Reyhani A, Mortazavi SZ, Mirershadi S, Moshfegh AZ, Parvin P, Nozad A. Hydrogen storage in decorated multiwalled carbon nanotubes by $\mathrm{Ca}, \mathrm{Co}, \mathrm{Fe}, \mathrm{Ni}$, and $\mathrm{Pd}$ nanoparticles under ambient conditions. J Phys Chem C 2011;115:6994-7001.

[4] Lin K-S, Mai Y-J, Li S-R, Shu C-W, Wang C-H. Characterization and hydrogen storage of surface-modified multiwalled carbon nanotubes for fuel cell application. J Nanomater 2012;2012:1-12.

[5] Liu C, Chen Y, Wu C-Z, Xu S-T, Cheng H-M. Hydrogen storage in carbon revisited. Carbon 2010;48:452-5.

[6] Cheng H-M, Yang Q-H, Liu C. Hydrogen storage in carbon nanotubes. Carbon 2001;39:1447-54.

[7] Banerjee S, Murad S, Puri IK. Hydrogen storage in carbon nanostructures: possibilities and challenges for fundamental molecular simulations. Proc IEEE 2006;94:1806-14.

[8] Mosquera E, Diaz-Droguett DE, Carvajal N, Roble M, Morel M, Espinoza R. Characterization and hydrogen storage in multiwalled carbon nanotubes grown by aerosol-assisted CVD method. Diam Relat Mater 2014;43:66-71.

[9] DoE Office of Energy Efficiency and Renewable Energy. Hydrogen storage. Available from: http://energy.gov/eere/ fuelcells/hydrogen-storage.

[10] Spyrou K, Gournis D, Rudolfa P. Hydrogen storage in graphene-based materials: efforts towards enhanced hydrogen absorption. ECS J Solid State Sci Technol 2013;2:M3160-9.

[11] Aboutabeli SH, Aminorroaya-Yamini S, Nevirkovets I, Konstantinov K, Liu HK. Enhanced hydrogen storage in graphene oxide-MWCNTs composite at room temperature. Adv Energy Mater 2012;2:1439-46.

[12] Jeing H, Feng Y, Chen M, Wang Y. Synthesis and hydrogenstorage performance of interpenetrated MOF-5/MWCNTs hybrid composite with high mesoporosity. Int J Hydrogen Energy 2013;38:10950-5.

[13] Deck CP, Vecchio K. Prediction of carbon nanotube growth success by the analysis of carbon-catalyst binary phase diagrams. Carbon 2006;44:267-75.

[14] Esconjauregui S, Whelan CM, Maex K. The reasons why metals catalyze the nucleation and growth of carbon nanotubes and other carbon nanomorphologies. Carbon 2009;47:659-69. 
[15] Liu H, Tagaki D, Chiashi S, Chokan T, Homma Y. Investigation of catalytic properties of $\mathrm{Al}_{2} \mathrm{O}_{3}$ particles in the growth of single-walled carbon nanotubes. J Nanosci Nanotechnol 2010;10:4068-73.

[16] Steiner SA, Baumann TF, Bayer BC, Blume R, Worsley MA, MoberlyChan WJ, et al. Nanoscale zirconia as a nonmetallic catalyst for graphitization of carbon and growth of singleand multiwall carbon nanotubes. J Am Chem Soc 2009;131:12144-54.

[17] Liang JJ, Huang Y, Oh J, Kozlov M, Sui D, Fang SL, et al. Electromechanical actuators based on graphene and graphene/ $\mathrm{Fe}_{3} \mathrm{O}_{4}$ hybrid. Adv Funct Mater 2011;21:3778-84.

[18] Hou CY, Zhang QH, Zhu MF, Li YG, Wang HZ. One-step synthesis of magnetically-functionalized reduced graphite sheets and their use in hydrogels. Carbon 2011;49:47-53.

[19] Xue YH, Chen H, Yu DS, Wang SY, Yardeni M, Dai QB, et al. Oxidizing metal ions with graphene oxide: the in situ formation of magnetic nanoparticles on self-reduced graphene sheets for multifunctional applications. Chem Commun 2011;47:11689-91.

[20] Shen JH, Zhu YH, Zhou KF, Yang XL, Li CZ. Tailored anisotropic magnetic conductive film assembled from graphene-encapsulated multifunctional magnetic composite microspheres. J Mater Chem 2012;22:545-50.

[21] He HK, Gao C. Supraparamagnetic, Conductive, and Processable Multifunctional Graphene nanosheets coated with high-density $\mathrm{Fe}_{3} \mathrm{O}_{4}$ nanoparticles. ACS Appl Mater Interfaces 2010;2:3201-10.

[22] Hernadi K, Fonseca A, Nagy JB, Bernaerts D, Fudala A, Lucas AA. Catalytic synthesis of carbon nanotubes using zeolite support. Zeolite 1996;17:416-23.

[23] Fonseca A, Hernadi K, Piedigrosso P, Colomer J-F, Mukhopadhyay K, Doome R, et al. Synthesis of single- and multi-wall carbon nanotubes over supported catalysts. Appl Phys A 1998;67:11-22.

[24] Sauerbrey TG. Verwendug von Schwingquarzen zur Wägung dünner Schichten und zur Microwägung. Z Phys 1959;155:206-22.

[25] Mecea VM. From quartz crystal microbalance to fundamental principles of mass measurements. Anal Lett 2005;38:753-67.

[26] Lucklum R, Hauptmann P. The quartz microbalance: mass sensitivity, viscoelasticity and acoustic amplification. Sens Actuators B 2000;70:30-6.

[27] Zhuo C, Hall B, Richter H, Levendis Y. Synthesis of carbon nanotubes by sequential pyrolysis and combustion of polyethylene. Carbon 2010;48:4024-34.

[28] Kumar M, Ando Y. Chemical vapor deposition of carbon nanotubes: a review on growth mechanism and mass production. J Nanosci Nanotechnol 2010;10:3739-58.

[29] Kubota A, Miyaoka H, Tsubota M, Shimoda K, Ichikawa T, Kojima Y. Synthesis and characterization of magnesium- carbon compounds for hydrogen storage. Carbon 2013;56:50-5.

[30] Li ZQ, Lu CJ, Xia ZP, Zhou Y, Luo Z. X-ray diffraction patterns of graphite and turbostratic carbón. Carbon 2007;45:1686-95.

[31] Singh DK, Iyer PK, Giri PK. Diameter dependence of interwall separation and strain in multiwalled carbon nanotubes probed by X-ray diffraction and Raman scattering studies. Diam Relat Mater 2014;43:66-71.

[32] Ferrari AC, Robertson J. Resonant Raman spectroscopy of disordered, amorphous and diamond like carbon. Phys Rev B 2001;64:075414.

[33] Brown SDM, Jorio A, Dresselhaus MS, Dresselhaus G. Observations of the $D$-band feature in the Raman spectra of carbon nanotubes. Phys Rev B 2001;64:073403.

[34] Belin T, Epron F. Characterization methods of carbon nanotubes: a review. Mater Sci Eng B 2005;119:105-18.

[35] Cho W, Schulz M, Shanov V. In: Suzuki Dr Satoru, editor. Kinetics of growing centimeter long carbon nanotube arrays, syntheses and applications of carbon nanotubes and their composites. InTech; 2013. http://dx.doi.org/10.5772/50837. ISBN: 978-953-51-1125-2.

[36] Shen K, Xu H, Jiang Y, Pietra T. The role of carbon nanotube structure in purification and hydrogen adsorption. Carbon 2004; $42: 2315-22$.

[37] Huang WZ, Zhang XB, Tu JP, Kong FZ, Ma JX, Liu F, et al. The effect of pretreatments on hydrogen adsorption of multiwalled carbon nanotubes. Mater Chem Phys 2002;78:144-8.

[38] Dillon AC, Jones KM, Bekkedahl TA, Kiang CH, Bethune DS, Heben MJ. Storage of hydrogen in single-walled carbon nanotubes. Nature 1997;386:377-9.

[39] Lim SC, Kim KK, Jeong SH, An KH, Lee S-B, Lee YH. Dual quartz crystal microbalance for hydrogen storage in carbon nanotubes. Int J Hydrogen Energy 2007;32:3442-7.

[40] Hou P-X, Xu S-T, Ying Z, Yang Q-H, Liu C, Cheng HM. Hydrogen adsorption/desorption behavior of multiwalled carbon nanotubes with different diameters. Carbon 2003;41:2471-6.

[41] Zhu H, Cao A, Li X, Xu C, Mao Z, Ruan D, et al. Hydrogen adsorption in bundles of well-aligned carbon nanotubes at room temperature. Appl Surf Sci 2001;178:50-5.

[42] Wang CL, Krim J, Toney MF. Roughness and porosity characterization of carbon and magnetic films through adsorption isotherm measurements. J Vac Sci Technol A 1989;7:2481-5.

[43] Ci L, Zhu H, Wei B, Xu C, Xu D. Annealing amorphous carbon nanotubes for their application in hydrogen storage. Appl Surf Sci 2003;205:39-43.

[44] Aomoa N, Bhuyan H, Cabrera AL, Favre M, Diaz-Droguett DE, Rojas S, et al. Rapid synthesis of carbon nanoparticles with an optimized combination of specific surface area and crystallinity by a plasma-assisted single-step process. J Phys D Appl Phys 2013;46:165501-9. 